\title{
El aislamiento social: connotaciones para las personas con discapacidad
}

\section{Social isolation: connotations for people with disabilities}

\author{
Rosa Ruffinellia, Sara Brito ${ }^{a}$
}

\begin{abstract}
Resumen
El aislamiento social, pensado desde la sociedad capitalista contemporánea, de la cual formamos parte, desarrolla su forma de vida a partir de condiciones de individualización y uniformizan la experiencia de la vida común, en este trabajo buscamos mostrar las connotaciones de lo que implica para las personas con discapacidad estas medidas. Las personas con discapacidad tienen necesidades singulares que se ponen a prueba en este momento pandémico, como la dependencia de la asistencia y la posible escasez de medicamentos durante la crisis; la presencia constante de cuidadores durante el período de distanciamiento físico y social; y acceso regular a los servicios de rehabilitación, situación que agudiza las precariedades en cuanto a su mejoramiento físico y afectivo, destacando que personas con discapacidad constituyen un sector de población heterogénea, y no uniforme como se plantean en las medidas impuestas por el estado.
\end{abstract}

Palabras clave: aislamiento social, persona con discapacidad, pandemia.

\begin{abstract}
Social isolation, thought from the contemporary capitalist society, of which we are a part, develops its way of life from individualization conditions and standardizes the experience of common life, in this work we seek to show the connotations of what these measures imply for the disabled people. People with disabilities have unique needs that are put to the test at this pandemic time, such as dependency on care and possible shortages of medicines during the crisis; the constant presence of caregivers during the period of physical and social distancing; and regular access to rehabilitation services, a situation that exacerbates the precariousness in terms of their physical and affective improvement, highlighting that people with disabilities constitute a heterogeneous sector of the population, and not uniform as stated in the measures imposed by the state.
\end{abstract}

a Universidad Nacional de Asunción, Facultad de Ciencias Sociales, Paraguay.

Correspondencia a: rruffinelli @yahoo.es

Recibido:

21 de mayo de 2020

Aceptado:

24 de junio de 2020

Artículo publicado en acceso abierto bajo la Licencia

Creative Commons.

\section{(c) (i)}

Cita:

Ruffinelli, R., \& Brito, S.

(2020). El aislamiento social: connotaciones para las personas con discapacidad.

Kera Yvoty: reflexiones sobre la cuestión social, 5 (número especial), 36-42.

Keywords: social isolation, disabled person, pandemic. 


\section{Introducción}

El planeta se encuentra paralizado a causa del COVID-19, un virus para el que no existe ninguna terapia en la actualidad y la única medida posible es el aislamiento físico y social.

Si bien se establece que las personas en situación de discapacidad configuran uno de los grupos vulnerables con más números dentro de casi todas las sociedades, también hay que destacar que son los que se encuentran con mayor desprotección en los sistemas de seguridad social y salud pública en general. Esta situación no es necesariamente inherente a las personas con discapacidad por sus características singulares, sino más bien a contextos de persistente exclusión, segregación y deshumanización.

En este trabajo se busca dar voz desde la academia a las personas con discapacidad, y como viven este momento histórico desde sus particularidades buscando de esta forma aportar para la construcción de una sociedad más inclusiva y menos individualista.

\section{El aislamiento social}

Hay mucho que decir sobre la relación entre la pandemia y la discapacidad. Resalta muchas de las desigualdades que enfrentan las personas con discapacidad, profundizando los problemas sociales y emocionales ya existentes o creando otros que aún no se han categorizado y que tal vez, después de pasado este periodo de crisis, surjan como nuevos "diagnósticos" que se relacionen al aislamiento físico y social.

Si bien la pandemia de COVID-19 amenaza a todos y todas en la sociedad, las personas con discapacidad se ven impactadas de manera desproporcionada debido a las barreras actitudinales, del entorno e institucionales que se reproducen en la respuesta de COVID-19 (Naciones Unidas, Oficina del alto comisionado, 2020).

El poner en cuestión, las representaciones simbólicas y estereotipos presentes, tensionar la invisibilidad y el acallamiento ubicando en primer plano las experiencias que han transitado las personas con discapacidad, a lo largo de sus vidas y con mas fuerza en este momento, que toca atravesar con la pandemia a las personas con discapacidad.

Las personas con discapacidad tienen necesidades singulares que se ponen a prueba en este momento pandémico, como la dependencia de la asistencia y la posible escases de medicamentos durante la crisis; la presencia constante de cuidadores durante el período de distanciamiento físico y social; y acceso regular a los servicios de rehabilitación, situación que agudiza las precariedades en cuanto a su mejoramiento físico y afectivo.

Las personas con discapacidad tienen más alto riesgo de mortalidad, morbilidad y pobreza como consecuencia del COVID-19, como lo señalan los primeros reportes de la Organización Mundial de la Salud que mencionaquelaspersonascondiscapacidad podrían recibir un mayor impacto negativo ante la pandemia (Organizacion Mundial de la Salud, 2020) .

El aislamiento físico y social, la interrupción de sus rutinas diarias en cuanto a la inclusión educativa y de rehabilitación y el acceso a sus cuidadores pueden ocasionar grandes crisis y aumento de la violencia física y psicológica.

\subsection{Acceso a servicios y cuidados}

Los sistemas de salud enfrentan grandes cargas, en todo el mundo, como resultado de este mortal virus y en respuesta se imponen restricciones a la circulación yal contacto físico y social para frenar el avance de esta pandemia, previéndose un impacto significativo sobre las mujeres, adolescentes y las niñas con discapacidad en relación al aumento de violencia de género y la pérdida de acceso a los servicios de salud (Fondo de Poblacion de las Naciones Unidas, 2020).

La discapacidad no es sinónimo 
de enfermedad, pero sí tienen mayores necesidades de cuidado en salud en general, lo que se traduce en más complicaciones en todos sus ámbitos, especialmente cuando hay "obstáculos para emplear algunas medidas básicas de higiene, como el lavado de las manos (por ejemplo, si los lavabos, las piletas o las bombas de agua son físicamente inaccesibles o una persona tiene dificultades físicas para frotarse bien las manos); dificultades para mantener el distanciamiento social debido al apoyo adicional que necesitan, la necesidad de tocar cosas para obtener información del entorno o para apoyarse físicamente; obstáculos para acceder a la información de salud pública” (Organizacion Mundial de la Salud, 2020, p. 2).

El aislamiento trajo consigo dificultades que se sumaron al peligro de ser contagiado. Desde la falta de cuidadores y las dificultades económicas formando un cóctel perfecto para comprometer aún más la salud emocional y la continuidad de los tratamientos de estas personas.

La única protección es el "distanciamiento social", un virus que genera una des socialización, una condición extrema que lleva a la incertidumbre de no saber que pasará y por ende, una angustia que se hace difícil de controlar en aquellas personas con fragilidad psíquica y emocional. La pandemia dejará problemas de salud mental en el mediano plazo. "La evidencia indica que cuando esto pase tendremos un montón de personas con síntomas persistentes de estrés agudo y postraumático" (Garabetyan, 2020, parr. 7).

Mantener la distancia y quedarse en casa implica una des-socialización extrema que aumenta el riesgo de desorden en el ámbito psíquico y afectivo en las personas con discapacidad y de sus cuidadores ante la angustia de no poder continuar con sus procesos de rehabilitación y contención de los profesionales que los asisten y acompañan.

\section{La uniformidad y el individualismo}

La sociedad capitalista contemporánea, de la cual formamos parte, desarrolla su forma de vida a partir de condiciones de individualización y uniformizan la experiencia de la vida común, lo que deja al margen de ello a las personas con discapacidad". Cuando todo se vuelve igual y la repetición es síntoma de adecuación normativa y se anula lo diferente, cuando el consenso neutraliza y todo deseo pondera lo semejante, la consecuencia es un orden donde todos piensan lo mismoy, entonces, nadie piensa" (Dipaola, 2020a, parr. 1).

Esta uniformidad es la que hace que el \#lávatelasmanos\# sea un eslogan que iguala a todos y en realidad las personas con discapacidad escapan justamente a la uniformidad, desde acciones sumamente sencillas para la normalidad, como lavarse las manos. "Como me lavo las manos si tengo una sola, y con ella hago todo, no puedo fregar mi mano" (funcionaria pública con agenesia de miembro superior izquierdo). "No puedo acceder a un lavabo en los espacios públicos porque el lavatorio está a la altura de los normales" (mujer movilizada en silla de ruedas).

"Las sociedades individualizadas son además heterogéneas y profundamente diversas, lo que significa que no se constituyen sobre el régimen de un núcleo esencial de costumbres y normas" (Dipaola, 2020b, parr. 12). La pandemia por Covid-19 nos muestra que no somos uniformes, que un gran porcentaje de la sociedad requiere ser atendida en su individualidad ya que su bienestar y en muchos casos la vida misma depende de la asistencia personal.

¿Qué pasa cuando los asistentes que los apoyan para el desarrollo de sus habilidades de la vida diaria, entre otras cosas, no pueden cumplir? ¿Qué pasa cuando hay crisis y aumento de sus síntomas en aquellas personas con sufrimiento psíquicos? Es prioridad cuidar la salud mental o solamente nos atenemos a cuidar la salud física y tener en cuenta sólo lo médico desde lo epidemiológico o infectológico, dejando que lo demás se resuelva como se 
pueda. Las transformaciones provocadas por COVID-19 cambiaron radicalmente las estructuras sociales y los modos de vinculación afectiva generando impactos significativos en las personas con discapacidad.

Teniendo en cuenta las diferentes formas en que se construye la discapacidad en las diferentes sociedades, lo que muestra una vez más las medidas para combatir el COVID-19, es el valor diferente de la vida de las personas, y que las personas mayores y las personas con discapacidad se consideran desechables y se les desaconseja buscar cuidados intensivos, o incluso se les informa que su hospitalización será rechazada, si bien no está escrito en los protocolos, forman parte del actuar de los profesionales de la primera línea y aun cuando los organismos internacionales desaconsejan estas medidas, como lo señala las Naciones Unidas "Las decisiones médicas deben basarse en evaluaciones clínicas individualizadas y necesidades médicas, y no en la edad u otras características como la discapacidad" (Naciones Unidas, 2020)

Es importante reflexionar sobre las respuestas que las personas con discapacidad y sus redes de relaciones han dado a los desafíos presentados durante la pandemia y cómo se experimenta la cuarentena. Esto incluye acceso variado a métodos preventivos, tratamientos $y$ atención para personas con discapacidades en medio de la pandemia.

"Una pandemia en sociedades individualizadas se funda también en perspectiva de esta flexibilidad. No estamos frente a una pandemia que nuclea a la sociedad de acuerdo a valores comunes, sino que globalmente asistimos al complejo de incertidumbres individuales sobre la circulación de un virus, y que definen a un nuevo tipo de individuo, el sujeto inmunizado por el riesgo anómico del contagio, un tipo de individuo inmune a la asistencia de otro, el individualismo formalizado" es la reflexión que nos deja el sociólogo argentino Esteban Dipaola con respecto a la coyuntura actual.
El 9 de marzo con la promulgación del Decreto Presidencial 3442/2020 se dispone la implementación de medidas preventivas ante la expansión del Coronavirus (COVID-19) y por medio de la Resolución № 099 del 19 de Marzo de 2020 del Ministerio de Salud se dispone el aislamiento preventivo general de la población, y con ello el inicio de las miles de situaciones que enfrentan la personas con discapacidad y sus familias. A continuación, algunas de ellas:

La frecuencia con la que se hace la terapia hace que los niños tengan una progresión regular y constante, a veces puede ser más lenta y otras un poco más rápida. Esto ha sido un cambio en el estilo de vida muy radical, puede haber una regresión y un impacto importante en lo que han venido trabajando en las terapias en los últimos meses. (Ultima Hora, 2020, parr. 14)

Usando los mecanismos y las señas que él ya tiene aprendidas, trabajo un poco la tolerancia a la frustración, porque todos nos sentimos frustrados. Imaginate lo que es vivir en un mundo de encierro y de silencio y ahora incorporar el componente del encierro físico. (Ultima Hora, 2020, parr. 17)

La situación de las personas con discapacidad en nuestro país tras el inicio de las restricciones y el distanciamiento social que iniciaron hace un mes atrás, arrojaron alarmantes datos que muestran entre otras cosas que el 39,6 \% quedo desempleado luego del inicio de la cuarentena. (ABC Color, 2020, parr. 2)

A partir de estas situaciones es indispensable revisar si estamos cuidando la salud mental, y damos importancia al aumento de la angustia y ansiedad que son cimientos para las enfermedades psíquicas 
que en muchos casos pueden hacer mayor estrago que las enfermedades físicas.

Las personas involucradas en la respuesta a la COVID-19 deben asociarse con personas con discapacidad para elaborar planes de respuesta, de manera que la información sea accesible y las personas con discapacidad no enfrenten discriminación en la prestación de servicios durante la pandemia de COVID-19. (Fondo de Población de las Naciones Unidas, 2020, parr. 19)

Las estrategias deben tener como premisa la prevención de la salud biopsico-social, los hábitos de cada individuo, dieta y actividad física, el distanciamiento social, el aislamiento y sus consecuencias como la depresión o ansiedad, soledad y marginación, agotamiento de los cuidadores.

\section{Reorganización familiar}

La familia de las personas con discapacidad que en estos tiempos se ven sobrepasadas con el rol de cuidador/as, maestras, amas de casas, profesionales y trabajadoras desde el hogar cumpliendo éste múltiple rol que esta contingencia nos obliga y para lo cual nadie les ha preparado.

"Las personas con discapacidades están en peligro en sus propios hogares, donde el acceso al apoyo y los servicios diarios pueden verse limitados debido a bloqueos, y algunos pueden sufrir mucho por estar aislados o confinados. Estos no son problemas irresolubles, pero requieren pasos específicos que se deben tomar o se deben hacer excepciones para evitar daños mayores" (Naciones Unidas, 2020).

La pandemia de COVID-19 está intensificando las diferencias y desigualdades experimentadas por las personas con discapacidad e incluso en circunstancias habituales, ya que ellas tienen menos probabilidades de acceder a la educación, la atención médica y las oportunidades de ingresos, o participar en sus comunidades. Estamos en riesgo y esto significa vivir en la incertidumbre del peligro constante y la catástrofe inminente, y en este aspecto el coronavirus (COVID-19) -y más allá de sus peculiaridades médicas y biológicas-, en un sentido social y político, es la experimentación del desarraigo de lo común, de la pérdida de lazo social estable (Dipaola, 202ob).

Las personas con discapacidad se encuentran entre las más afectadas porque son las más invisibilizadas además de enfrentar una falta de información de salud pública accesible, así como barreras significativas para implementar medidas básicas de higiene y acceso a la comunicación inclusiva y es la familia la que debe ir sorteando todas estas situaciones.

En cuanto al acceso de la educación y la implementación de la educación virtual y en el hogar, los jóvenes y niños con discapacidad tiene bastante limitado este derecho, ya que todos los establecimientos han cerrado sus puertas entregando los contenidos del aprendizaje de manera virtual y teniendo en cuenta que la mayoría de los textos escolares y materiales publicados para la entrega virtual no son accesibles, además de las conexiones de internet, la faltadeequipamientosaccesibles y programas adecuados y adaptados y es allí donde nuevamente la familia debe hacer frente y paliar estas necesidades conforme a su recursos internos.

Las dificultades en el acceso a la información y comunicación se hace más evidente en estos momentos de pandemia y la familia debe asumir también este rol, de trasmisor de información ya que las mismas son pocos accesibles y se debe hacer el esfuerzo para asegurar que las personas con discapacidad puedan acceder sin barreras de la manera más práctica posible a ellas.

\section{Conclusión}

La universidad en su rol de formadoras de nuevas generaciones de profesionales con pensamiento crítico, debe aportar hacia la configuración de miradas hacia lo otro, abandonando los estereotipos y 
juicios basados en opiniones erróneas, puede ser un primer paso para establecer formas equitativas de convivencia en una sociedad diversa.

Es importante destacar que las personas con discapacidad constituyen un sector de población heterogéneo, pero todas tienen en común que, en mayor o menor medida, precisan de una protección singularizada en el ejercicio de los derechos humanos y libertades básicas, debido a las necesidades específicas derivadas de su situación de discapacidad y de pervivencia de barreras que evitan su participación plena y efectiva en la sociedad, en igualdad de condiciones con las demás personas.

Este aislamiento social puso, una vez más, en evidencia las vulnerabilidades de las personas con discapacidad y que no solamente con leyes, decretos, resoluciones, y ordenanzas se van a lograr el tan anhelado cumplimiento de los derechos, sino a partir de la construcción de formas de ver y entender la discapacidad con miras a transformar la realidad y que la nueva normalidad, ser mas inclusiva y menos individualista.

\section{Referencias}

Ultima Hora. (1 de abril de 2020). Covid-19: El doble encierro de las personas con autismo en Paraguay. https://www. ultimahora.com/covid-19-el-dobleencierro-las-personas-autismoparaguay-n2877851.html

ABC Color. (6 de abril de 2020). El $40 \%$ de personas con discapacidad quedaron desempleadas durante la cuarentena. https://www.abc.com. py/nacionales/2020/o4/o6/el-40de-personas-con-discapacidadquedaron-desempleadas-durantecuarentena/
Dipaola, E. (2020a). Teoría social y coronavirus Cultura visual y pandemia. Bordes. Revista de Politica, derecho y Sociedad. http://revistabordes.unpaz. edu.ar/cultura-visual-y-pandemia/

Dipaola, E. (Mayo de 202ob). Individualismo y pandemia: consecuencias y riesgos globales. Reflexiones Marginales. https://revista.reflexionesmarginales. com/individualismo-y-pandemiaconsecuencias-y-riesgos-globales/

Fondo de Poblacion de las Naciones Unidas. (12 de Mayo de 2020). La pandemia aumenta la vulnerabilidad de las personas con discapacidad. https://www.unfpa.org/es/news/lapandemia-aumenta-la-vulnerabilidadde-las-personas-con-discapacidad

Garabetyan, E. (25 de abril de 2020). Especialistas advierten "epidemia" de estrés postraumático por la cuarentena. Perfil. https://www.perfil. com/noticias/ciencia/adviertenepidemia-de-estres-postraumaticopor-la-cuarentena.phtml

Naciones Unidas . (30 de Abril de 2020). Noticias ONU. https://news.un.org/es/ story/2020/04/1473702

Naciones Unidas. Oficina del Alto Comisionado. (2020). COVID-19 y los derechos de las personas con discapacidad: directrices. https:// www.ohchr.org/Documents/Issues/ Disability/COVID-19_and_The_ Rights_of_Persons_with_Disabilities_SP.pdf

Organizacion Mundial de la Salud. (2020). Disability considerations during the COVID-19outbreak. OMS/OPS. https:// apps.who.int/iris/handle/10665/332015 


\section{Sobre las Autoras}

Rosa Ruffinelli

Doctoranda en Educación, UNA, Master en Trabajo Social, Licenciada en Trabajo Social por la UNA, Especialista en Educación y Rehabilitación con Enfoque Biopsicosocial, Docente Investigador de la UNA/FACSO, docente de la UNA/FENOB. Miembro del GT CLASCO Estudios Críticos en Discapacidad.

\section{Sara Brito}

Licenciada en Psicología. UNA. Jefa del Departamento de Psicología de Senadis 2013- 2019. Encargada de Capacitación y Docencia, Senadis. Docente Universitaria. Especialista en Didáctica Universitaria y Bioética UNA. Diplomado Superior. Políticas Públicas en 1era Infancia. FLACSO- OEI. Especialista en Rehabilitación de PcD con enfoque Biopsicosocial. Universidad Andrés Bello, Chile. 